This item was submitted to Loughborough's Research Repository by the author.

Items in Figshare are protected by copyright, with all rights reserved, unless otherwise indicated.

\title{
Hybridization of Nafion membranes by the infusion of functionalized siloxane
} precursors

PLEASE CITE THE PUBLISHED VERSION

PUBLISHER

(C) Elsevier

LICENCE

CC BY-NC-ND 4.0

\section{REPOSITORY RECORD}

Lavorgna, Marino, Leno Mascia, Giuseppe Mensitieri, Marianne Gilbert, and Giuseppe Scherillo. 2007. "Hybridization of Nafion Membranes by the Infusion of Functionalized Siloxane Precursors". figshare. https://hdl.handle.net/2134/2998. 
This item was submitted to Loughborough's Institutional Repository by the author and is made available under the following Creative Commons Licence conditions.

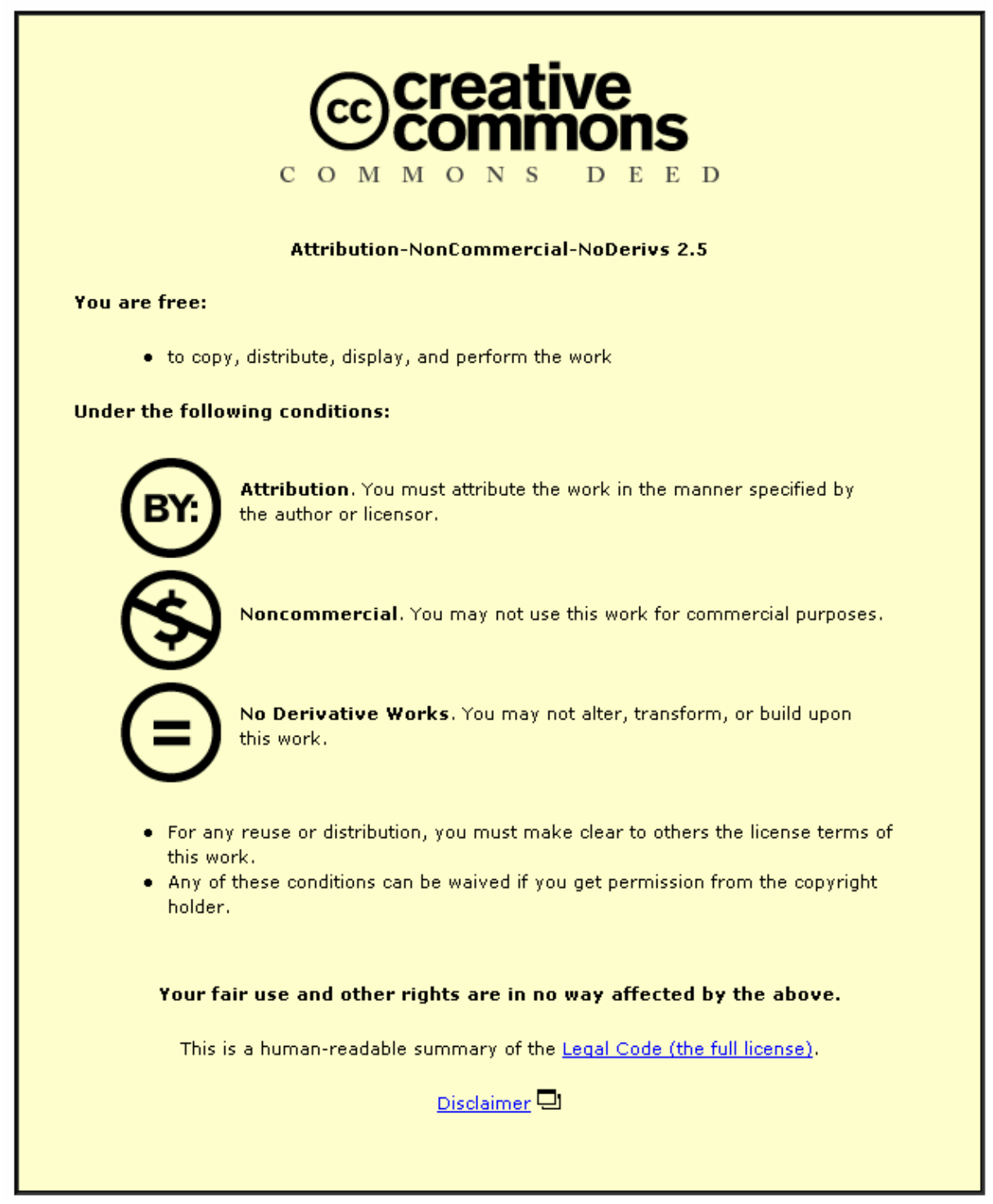

For the full text of this licence, please go to: http://creativecommons.org/licenses/by-nc-nd/2.5/ 


\title{
HYBRIDIZATION OF NAFION MEMBRANES BY THE INFUSION OF \\ FUNCTIONALIZED SILOXANE PRECURSORS
}

Marino Lavorgna ${ }^{1}$, Leno Mascia $^{2}$, Giuseppe Mensitieri $^{3}$, Marianne Gilbert ${ }^{2}$, Giuseppe Scherillo ${ }^{3}$, and Biagio Palomba ${ }^{3}$.

1 Institute of Composite and Biomedical Materials, National Research Council, P.le E.Fermi1, Loc Granatello, 80055 Portici (NA), Italy

2 Institute of Polymer Technology and Materials Engineering, Loughborough University, Loughborough LE11 TU, (UK)

3 Department of Material Engineering and Production, University Federico II, Naples-80125 Italy

\begin{abstract}
Polysiloxane modified hybrid membranes were prepared by introducing pre-swelled commercial Nafion membrane into a sol-gel precursor solution, consisting of a pre-hydrolyzed mixture of tetraethoxysilane (TEOS) and a mercaptan functionalized organoalkoxysilane. The structure of the polysiloxane network was changed by altering the ratio of the two silane components within the precursor solution. The mercaptosilane modifier was used to provide an additional source of acidic Bronsted sites through the oxidisation of the mercaptan groups to sulfonic acid groups.

The physical and chemical properties of the hybrid membranes were examined by TGA, FTIR and SEM analysis. The water vapour sorption and proton conductivity characteristics were evaluated at temperatures up to $70^{\circ} \mathrm{C}$ and with water activity in the region of 0.4 to 1 .
\end{abstract}


It was found that the polysiloxane network alters the water vapour sorption mechanism of the Nafion membrane, resulting in an increase in the equilibrium amount of water absorbed in the middle range of water activity (0.4-0.6). At the same time, the increased water absorption capability produced a concomitant increase in ionic conductivity at low water activities.

\section{Keywords:}

\section{INTRODUCTION}

Polymer electrolyte fuel cells (PEFCs) are increasingly acquiring greater consideration for high efficiency power generators [1,2]. The main requirements of fuel cell membranes are high proton conductivity, chemical stability and retention of mechanical strength and ductility over long periods of time. At present only perfluorosulfonic acid membranes, such as Nafion, meet these requirements and, for this reason, they are extensively used in PEFCs [3]. These membranes, however, are very expensive and display a high methanol crossover, which is a major drawback in direct methanol fuel cells applications (DMFC). Furthermore the rapid loss of absorbed water at temperatures above $80^{\circ} \mathrm{C}$ causes a concomitant deterioration of their proton transport capability, which compromises their use in hydrogen fuel cells. In the case at hand the loss of water at the anodic membrane electrode-interface is also a consequence of the electro-osmotic water drag, which is already effective at temperatures lower than $80^{\circ} \mathrm{C}$ [4-7].

A strategy that has been suggested for improving the high temperature performance of existing perfluorosulfonic polymer membranes is the incorporation of dispersed nanostructured hygroscopic oxides, such as $\mathrm{SiO}_{2}, \mathrm{TiO}_{2}, \mathrm{ZrO}_{2}$ [8]. These nanocomposite membranes exhibit higher water sorption characteristics, particularly at high temperatures, which allow the proton conductivity 
capability to be maintained even at temperatures above $100^{\circ} \mathrm{C}$, within the working range of water activity operating in hydrogen fuel cells [9-11].

It should be possible to increase the tortuosity of the methanol pathways without affecting appreciably the proton conductivity mechanism by producing bicontinuous-phase nanocomposites, generally known as organic-inorganic hybrids [12-14].

It has been reported that, in the production of hybrid silica- Nafion membranes, the presence of inorganic siloxane domains could interfere with the structure of the ionic clusters and reduce accordingly the proton conductivity measured at high water activity. Nevertheless the performance of organic-inorganic hybrid membranes for hydrogen fuel cells was found to be better than that of the unmodified Nafion [8]. The proton conductivity of Nafion membranes is strictly dependent on the dimensions of the channels connecting the ionic clusters, which is related to the water absorption characteristics of the membrane $[15,16]$. It has been suggested that degree of swelling of installed membranes is reduced by the constraints exerted by the sealing pressure of the electrodes, which increases the chemical potential of the water inside the membrane and reduces the amount of water sorption at a given external activity. This effect is alleviated by the introduction of inorganic domains by the production of a hybrid structured membranes In these systems the presence of bicontinuous inorganic nanostructured domains reduce the mobility of the polymer chains and stabilizes the dimensions of the ionic channels within the membranes. [8].

Moreover the presence of large amounts of hydroxylated siloxane domains in hybrid structured membranes is expected to enhance the hydrophilic character of the surface of the membrane, thereby reducing the Schoeder's effect by improving the re-hydration characteristics in humidified hydrogen environments [7]. This offsets the drying effect of the membrane in hydrogen fuel cells due to the electro-osmotic water drag process.

In the present work we have investigated the effects of different amounts of functionalised siloxanehybrid nanostructures in Nafion membranes, obtained by the infusion of a precursor solution into a pre-swelled membrane [17]. In particular these precursor solutions were based on mixtures of 
tetraethoxisilane and a mercaptolkoxysilane. The mercaptoalkoxysilane was considered as an additional source of Bronsted acid sites because the $\mathrm{SH}$ groups of the siloxane network can be oxidized to sulfonic groups $\left(\mathrm{SO}_{3} \mathrm{H}\right)$. Not only would this increase the proton concentration in the ionic clusters of the membrane but would also have an indirect effect on the proton mobility, by increasing the water sorption capability of the membrane.

\section{EXPERIMENTAL}

\section{Membrane pre-treatment}

Nafion 117 membranes (provided by Quintech) were hybridized by the introduction factionalised siloxane networks in a manner similar to the method used by Mauritz et al [9]. Accordingly Nafion films were previously activated by a standard treatment consisting of the following steps: i) Boiling in $3 \%$ hydrogen peroxide solution for $1 \mathrm{~h}$, ii) Water rinsing for $1 \mathrm{~h}$ at $80^{\circ} \mathrm{C}$, iii) Boiling in $0.5 \mathrm{M}$ sulphuric acid for $1 \mathrm{~h}$, and iv) Additional water rinsing at $80^{\circ} \mathrm{C}$ for $1 \mathrm{~h}$ to remove acid residues.

The activated Nafion films were dried under vacuum at $80^{\circ} \mathrm{C}$ for 1 day. Prior to the treatments the membranes were swelled in a water-ethanol-glycerol mixture $\left(35: 28: 37\right.$ weight ratio) at $40^{\circ} \mathrm{C}$ for 3 days. The precursor solution of the functionalized polysiloxane component was prepared by mixing tetraethoxysilane (TEOS from Aldrich) and $\gamma$-propyl mercaptan triethoxysilane (MPTMS from Aldrich), acidified $\mathrm{H}_{2} \mathrm{O}(2 \% \mathrm{wt} / \mathrm{wt} \mathrm{HCl}$ solution), ethanol and glycerol. Weight ratios of TEOS/MPTMS 65/35 and 35/65 were used, and the solvent weight ratio $\mathrm{H}_{2} \mathrm{O}(2 \% \mathrm{wt} / \mathrm{wt} \mathrm{HCl})$ : EtOH : glycerol was equal to 35:28:37. The water in the precursor solution was used at equal molar amounts to the total alkoxysilane groups present in the precursor mixture (TEOS+MPTMS). The precursor solution was then mixed for 5 minutes at room temperature in a vessel fitted with a magnetic stirrer. The swelled membranes were dipped in the precursor solution for 5 and 20 minutes respectively at $60^{\circ} \mathrm{C}$. In this process the alkoxy silane mixture diffuses into the membrane, and the alkoxide groups hydrolyze and condense to produce a siloxane network. The temperature 
and ageing time conditions used were specially chosen to avoid the formation of undesirable disulphide species [18].

The membranes were then rinsed in ethanol to remove residues of precursor solution from the surface and cured for 24 hours at $80^{\circ} \mathrm{C}$, and a further 3 hours at $100^{\circ} \mathrm{C}$ in an oven. Afterwards the membranes were submitted to the oxidation treatment according to the procedure described previously for the activation of unmodified Nafion membranes. This step activates the $\mathrm{SO}_{3} \mathrm{H}$ groups in the clusters of the Nafion membranes and promotes the oxidation of the $\mathrm{SH}$ groups in the siloxane network to $\mathrm{SO}_{3} \mathrm{H}$ groups [19, 20].

\section{Chemical and physical characterization}

ATR-IR spectra were collected on a Nexus Thermo Nicolet equipped with an attenuated total reflection accessory using a $\mathrm{ZnSe}$ crystal. Infrared spectra were collected as the average of 64 scans with a resolution of $4 \mathrm{~cm}^{-1}$ over the range 4000 to $650 \mathrm{~cm}^{-1}$.

Control samples of polysiloxane were produced from the alkoxysilane precursor solutions in the form of cast films heated at $60^{\circ} \mathrm{C}$ till gelification occurred (around 24 hours) and curing at $100^{\circ} \mathrm{C}$ for 3 hours. Small samples taken both before and after the oxidation treatment, were cast as films, dried, ground to a fine powder and then compressed into a $\mathrm{KBr}$ disc for FTIR analysis in transmittance mode.

Thermogravimetric analysis of the Nafion membranes and the corresponding hybrid membranes was performed with a Du Pont 951 Thermogravimeter Analyzer from 120 to $700^{\circ} \mathrm{C}$ at a heating rate of $10 \mathrm{~K} / \mathrm{min}$ in a $\mathrm{N}_{2}$ atmosphere, after an initial isothermal treatment at $120^{\circ} \mathrm{C}$ to remove the free water.

The membranes were examined with a scanning electron microscope (SEM) (Leica Cambridge Stereoscan S440) coupled with a probe for Energy Dispersive Scanning (EDS) to study the changes in morphology resulting from the hybridization with the functionalized siloxanes and to verify the 
homogeneity of silica throughout the sample thickness. The membranes were cryogenically fractured in liquid $\mathrm{N}_{2}$ for the SEM examinations.

\section{Ionic exchange capacity}

The ionic exchange capacity (IEC) was determined by titration. The membranes were dried at $80^{\circ} \mathrm{C}$ for $24 \mathrm{~h}$, were weighed and then dipped in a $1 \mathrm{M} \mathrm{NaCl}$ solution at $80^{\circ} \mathrm{C}$ for $24 \mathrm{~h}$ to exchange the $\mathrm{H}^{+}$ ions with $\mathrm{Na}^{+}$. The solution was titrated to the end point with $0.1 \mathrm{M} \mathrm{NaOH}$ using Phenolphthalein as indicator. The IEC was calculated using the dry weight of the samples and the quantity of exchanged protons, i.e. $\mathrm{IEC}=$ mol $\mathrm{H}^{+}$per gram dry membrane.

\section{Proton conductivity measurements.}

The proton conductivity of the membranes was measured using the Membrane Conductivity Test Cell manufactured by BekkTech Company, which makes it possible to measure the conductivity of the membrane in the longitudinal direction by minimizing the resistance at the interface between electrodes and membrane [21].

The measurement cell was connected to an electrochemical workstation consisting of a potentiostat and a frequency response analyzer (Solartron SI 1280B). A four probe system was chosen, so that measurements of the bulk conductivity of the membrane could be made by ensuring that a homogeneous current density along the thickness for the portion of the sample between the two inner electrodes VERIFICA!!!. Control of the humidity and temperature was obtained by placing the Membrane Conductivity Test Cell in a water jacketed cell working with a controlled humidity environment. The measurements were carried in the temperature range between 30 and $80^{\circ} \mathrm{C}$ and at a vapour water activity of 1 . Furthermore ionic conductivity measurements at lower water activity were also performed by using in the water jacketed cell saturated solutions of $\mathrm{NaCl}$ and $\mathrm{MgCl}_{2}$ 
which were able to set the water activity in the ranges $0.6-0.8$ and $0.4-0.5$ respectively for the complete temperature range investigated.

\section{Water vapour sorption measurements.}

Water vapour sorption isotherms were obtained using an apparatus consisting of a quartz spring placed in a water jacket glass cell with service lines to a solvent reservoir and to a pressure transducer [22].

Before each test a reservoir flask, connected with a valve to the sorption cell, was pressurized with water vapour at a fixed pressure connecting it to the vapour phase of a degassed liquid water reservoir. The quartz spring used for these experiments has accuracy to $5 \mathrm{mg} / \mathrm{cm}$. The extension of the spring was measured using a travelling microscope capable of measuring displacements to 0.005 $\mathrm{mm}$ accuracy. Water vapour activity was expressed as the ratio $\mathrm{p} / \mathrm{p}_{\mathrm{o}}$, where $\mathrm{p}$ is the actual pressure of water vapour and $\mathrm{p}_{\mathrm{o}}$ is the water vapour pressure at the test temperature (assuming ideal behaviour of the vapour). Water sorption measurements of the samples were carried out at 40, 60 and $70^{\circ} \mathrm{C}$ in the range of water vapour activity between 0 and 0.8 , corresponding to the different extents of hydration of hydrogen fuel cells in the transient start-up phase and different working conditions. The water activity 0.8 is the maximum activity attainable in the sorption apparatus without condensation problems.

\section{RESULTS}

\section{Infrared spectroscopy characterization}

FT-IR transmission spectra of the functionalized polysiloxane control i.e. not infused in the Nafion membrane collected before and after the oxidation process are shown in Figure 1. The principal 
absorbance peaks of the spectra are reported in Table $1[17,23]$. The data indicate that the intensity of the band at $2575 \mathrm{~cm}^{-1}$ ascribed to the $\mathrm{SH}$ groups present in the organotrialkoxy silane component, decreases as a result of their oxidation to $\mathrm{SO}_{3} \mathrm{H}$ groups. A small $\mathrm{SH}$ absorbance peak is still observable, however, at the end of the treatment, demonstrating that under the oxidation conditions used the conversion $\mathrm{SH}$ to $\mathrm{SO}_{3} \mathrm{H}$ groups is not complete. The absorbance peaks related to asymmetric and symmetric stretching modes of the $\mathrm{SO}_{3}{ }^{-}$groups, which are expected at 1040 and $1100 \mathrm{~cm}^{-1}$, are not evident as they superimposed onto the intense peaks of the silica network, composed mainly of SiOSi bonds.

Figure 2 shows the FTIR-ATR spectra of the Nafion 117-siloxane hybrid membranes for 20 and 5 minutes impregnations respectively and with MPTMS/TEOS weight ratio equal to 35/65.

The spectra show that while the major IR vibrational features of Nafion polymer are present in all the samples (see Table 1), the presence of the polysiloxane component in the hybrid membranes affects the shape of the absorbance bands in the region between 900 and $1200 \mathrm{~cm}^{-1}$. In particular it is evident that for the unmodified Nafion the absorbance of the hybrid membranes is significantly increased at around $1080 \mathrm{~cm}^{-1}, 1040 \mathrm{~cm}^{-1}$ and at $900-940 \mathrm{~cm}^{-1}$. Comparing these with the features of the pure polysiloxane component identified in Figure 1 it is clear that these wavenumbers correspond to the most important vibrational bands of the inorganic network. The spectroscopic results confirm that the polysiloxane network is present in the hybrid membranes even after the oxidation reactions to convert $\mathrm{SH}$ to $\mathrm{SO}_{3} \mathrm{H}$ groups. In other words although hydrolytic reactions may have taken place during the oxidation treatment, these have not resulted in the complete breakdown of the siloxane network. 


\begin{tabular}{ll}
\hline Absorbance peaks & Wavenumbers, $\mathbf{~ c m}^{-1}$ \\
\hline Nafion 117 & 1200 \\
$v_{\mathrm{as}}\left(\mathrm{CF}_{2}\right)$ & 1143 \\
$v_{\mathrm{s}}\left(\mathrm{CF}_{2}\right)$ & 1056 \\
$v_{\mathrm{s}}(\mathrm{SO})$ & 980 \\
$v_{\mathrm{s}}(\mathrm{CFRCF})$ & 968 \\
$v_{\mathrm{s}}(\mathrm{COC})$ & \\
\hline Polysiloxane network & 1080 \\
\hline$v_{\mathrm{s}}(\mathrm{SiOSi})$ cyclic oligomers & 1040 \\
$v_{\mathrm{s}}(\mathrm{SiOSi})$ linear oligomers & 1130 \\
$v_{\mathrm{s}}(\mathrm{SiOSi})$ siloxanes $(\mathrm{SiO})_{\mathrm{n}}$ & 640 \\
$v_{\mathrm{s}}(\mathrm{SiOSi})$ siloxanes $(\mathrm{SiO})_{\mathrm{n}}$ & $900-980$ \\
$v_{\mathrm{s}}(\mathrm{SiOH})$ & 2575 \\
$v_{\mathrm{s}}(\mathrm{SH})$ & $2950-2850$ \\
$v_{\mathrm{s}}(\mathrm{CH})$ & $1410,1430,1455$ \\
$v_{\mathrm{s}}(\mathrm{CH})$ & $3000-3700$ \\
$v_{\mathrm{s}}\left(\mathrm{H}_{2} \mathrm{O}\right)$ broad &
\end{tabular}

Table 1: IR absorbance peaks of Nafion 117 (collected by ATR) and polysiloxane.

\section{Thermogravimetric analysis}

The thermograms for the unmodified Nafion and those for the hybrid membranes (respectively 5 and 20 minutes impregnation time and MPTMS/TEOS weight ratio 35/65) are shown in Figure 3. These indicate that all the membranes retain more than $95 \%$ of their weight up to $280^{\circ} \mathrm{C}$. Samms et al [24] demonstrated that for an unmodified Nafion membrane weight losses occurring in the range between $120^{\circ} \mathrm{C}$ and $250^{\circ} \mathrm{C}$ involve residual water embedded in the ionomeric cluster structure, which are strongly bound to the sulfonic groups. For the case of hybrid membranes some loss can be attributed to residual ethanol and glycerol. At temperatures above $250^{\circ} \mathrm{C}$ all membranes start to undergo thermal degradation. In the thermogram of the unmodified Nafion there are two thermal activated degradation processes. The first at around $320^{\circ} \mathrm{C}$ is due to the decomposition of sulfonic acid groups, while the second one at around $500^{\circ} \mathrm{C}$ is related to the decomposition of the $\mathrm{CF}_{2}$ backbone of the Nafion polymer [25]. For the case of the hybrids there is a change in the decomposition temperatures relative to the unmodified Nafion. In particular, the first activated 
decomposition temperature increases to $330^{\circ} \mathrm{C}$ while the thermal decomposition temperature of the backbone polymer decreases down to $460^{\circ} \mathrm{C}$ [26].

The increase in the onset decomposition temperature for the $\mathrm{SO}_{3} \mathrm{H}$ groups is a typical effect of observed with silica-polymer hybrids, which is attributed to the reduced diffusion rate of both oxygen and volatile oxidation products $[27,28]$. In this case, however, the effect is limited by the catalytic effect that the sulphur oxides produced from the thermal activated decomposition of sulfonic acid groups can have on the degradation of silica network [26].

The reduction in the decomposition temperature for the fluorocarbon chains, on the other hand, is characteristic of the accelerated degradation through the reactions of CF groups with siloxanes to produce the highly volatile $\mathrm{SiF}_{4}$

The residual weight at high temperatures provides a reasonably accurate estimate of the inorganic silica content expressed as $\mathrm{SiO}_{2}$ obtained through decomposition of the entire polysiloxane network.

\begin{tabular}{ccc}
\hline Immersion Time (min) & $\begin{array}{c}\text { MPTMS/TEOS weight } \\
\text { ratio }\end{array}$ & Residue (\% wt) \\
\hline 5 & $35 / 65$ & 8.1 \\
20 & $35 / 65$ & 10.8 \\
5 & $65 / 35$ & 7.1 \\
20 & $65 / 35$ & 9.2 \\
\hline
\end{tabular}

Table 2: Residue from the thermal oxidation of hybrid membranes

The data in Table 2 show that the residue increases with the immersion time of the membranes in the siloxane precursor solution. Furthermore the precursor solution with the higher weight ratio MPTMS/TEOS gives lower amounts of thermal degradation residues. This is attributed to the 
greater network density of the polysiloxane domains, and possibly also to the lesser extent of hydrolytic degradation taking place in the oxidation treatment of the hybrid membranes to convert the $\mathrm{SH}$ to $\mathrm{SO}_{3} \mathrm{H}$ groups. It is worth adding that the actual polysiloxane content is higher than the residues reported in Table 2 owing to the destruction of the organic matter in the TGA experiments.

\section{SEM - EDS data}

The micrographs taken on the cross-section of both the unmodified Nafion membrane and the silica-hybrid membrane obtained from system MPTMS/TEOS 65/35 with immersion time of 20 minutes are shown in Figure 4. At the level of magnification used it is possible to observe a morphological heterogeneity due to the presence of the polysiloxane network. In fact, the unmodified Nafion shows a smooth fracture surface while the hybrid membrane shows a surface with "grainy" morphology which can be attributed to the polysiloxane domains.

As for the uniformity of the siloxane domains through the thickness of the membranes EDS analysis has revealed the existence of an asymmetric profile with a slightly lower silicon content in the middle, similar to the findings of Mauritz et al. [11].

\section{Ion exchange capacity}

The values of the ionic exchange capacity of the unmodified Nafion and corresponding hybrid membranes are reported in Table 3. These show that the hybrid membranes exhibit a lower ion exchange capacity than the unmodified Nafion and that the IRC values of hybrid membranes produced with MPTMS/TEOS weight ratio of $65 / 35$ are higher than those obtained with MPTMS/TEOS ratio equal to 35/65. 


\begin{tabular}{rll}
\hline Membranes & $\begin{array}{l}\text { IEC } \\
\text { (meq/gr) }\end{array}$ \\
\hline Unmodified Nafion 117 & 0.92 \\
Hybrid M/T 65/35 - 5 min immersion & 0.81 \\
“ $\mathrm{M} / \mathrm{T} 65 / 35-20 \mathrm{~min}$ “ & 0.85 \\
“ $\mathrm{M} / \mathrm{T} \mathrm{35/65}-5 \mathrm{~min}$ “ & 0.78 \\
“ $\mathrm{M} / \mathrm{T} \mathrm{35/65}-20 \mathrm{~min} \quad$ “ & 0.8 \\
\hline
\end{tabular}

Table 3: Ionic exchange capacity of Nafion 117 and corresponding siloxane hybrids

The IEC data in table 3 show that the siloxane hybrid membranes contain a lower number of exchangeable protons than the original (unmodified) Nafion.

The theoretical ionic exchange capacity of the siloxane hybrid membranes can be calculated as the weighted average of the values of each component, i.e.

$\mathrm{IEC}_{\text {hybrid }}=($ mass fraction Nafion $) \cdot \mathrm{IEC}_{\text {Nafion }}+($ mass fraction siloxane $) \cdot \mathrm{IEC}_{\text {Siloxane }}$

The mass fraction value of the siloxane phase lie between two extremes, the residue from TGA experiments and the initial MPTMS/TEOS weight ratios used in the sol-gel precursor solutions. The estimated IEC $_{\text {Silica }}$ values vary between 0.1 and $0.5 \mathrm{~m}_{\mathrm{eq}} / \mathrm{gr}$. Although these IEC values are rather low, they can have an appreciable effect on the water vapour sorption characteristics and the related ionic conductivity of the hybrid membranes.

\section{Water vapour sorption}

In Figures 5, 6 are shown the water sorption isotherms at 40,60 and $70^{\circ} \mathrm{C}$ for both the unmodified Nafion membrane, and the pre-swelled Nafion membrane.

\section{Figure 5,6}

The pre-swelled Nafion membrane refers to the Nafion membrane subjected to similar swelling treatment carried out to introduce the functionalized siloxane domains in the hybrid membranes. 
The lower water absorption of the pre-swelled Nafion (see Figure 6), relative to the unmodified commercial Nafion, is a consequence of the possible changes in the morphological structure of the ionic clusters.

Figures 7 and 8 show the water sorption isotherms at $40-60-70^{\circ} \mathrm{C}$ for the two Nafion-siloxane hybrids prepared with MPTMS/TEOS ratios of 35/65 and 65/35. These are abbreviated to M/T $35 / 65$ and $\mathrm{M} / \mathrm{T} 65 / 35$.

\section{Figure 7,8}

The membrane displays the typical sigmoidal sorption isotherms of ionomers. The sorption of water molecules involves two populations of molecules, those tightly bound to specific groups (sulfonic and silanol groups, in this case) and those absorbed by entropic effects. The first can be considered a chemisorption process and can be described either with the use of models specifically developed for ionomers [7] or using finite-layer BET [30]. The latter is related to the physical mixing of water with the ionomer and is controlled by both the elastic response of the polymer-siloxane network, which resists swelling due to constraints imposed by the crosslinks, and by the presence of clusters of ionic groups on the polymer and silica backbone derived from the mercaptan groups in the MPTS component $[7,31]$. Therefore, at low activities, the downward concavity observed in the sorption isotherms can be related to the binding of the strongly interacting first shell of water molecules to sulfonic groups and hydrophilic silica, while the upward concavity which is observed at high activities is mainly due to binding of water molecules in the formation of additional solvated shells and to water-polymer mixing in accordance with Flory-Rehner theory [32].

It is worth noting that the increase in concentration of such 'free' water molecules occurring at high activities is a prerequisite for a high protonic conductivity in hydrated membranes [8]. 
As can be inferred by the reported sorption isotherms, Nafion samples containing the inorganic phase display a higher contribution of adsorption on specific sites (downward concavity region) because of the presence of hydrophilic siloxane phase, which contributes to the initial adsorption capability of the material.

The effect of the temperature on the sorption isotherms of ionomeric systems is generally complex. Adsorption occurring on specific interaction sites and within the excess free volume regions, and water clustering, are all exothermic phenomena. Moreover, since the elastic response of an elastomeric network becomes more effective as the temperature increases (Flory-Rehner), a further reduction in the amount of sorbed water is also expected with increasing temperature. In contrast, polymer-water mixing is endothermic and, therefore, would favour an increase of the amount of water absorption with temperature.

Another relevant point is that the thermal activation of the chain mobility in the polysiloxane domains might cause a re-organization of its ionic groups and network structure within the clusters, which would produce a significant modification in the water sorption behaviour of the membranes. This latter effect seems to play a crucial role in the variation of the water sorption with temperature of the hybrid samples, contrary to the typically behaviour of unmodified Nafion, which is almost athermal.

The data in Figure 6 show that the water sorption isotherms of pre-swelled Nafion membranes are not sensitive to changes in temperature. This is a well known behavior of commercial unmodified Nafion, and can be regarded to be a consequence of the trade-off between the endothermic mixing of polymer with water, the increasing of elastic contribution of network with temperature, and also the exothermic nature of water clustering together with the sorption on specific sites described earlier.

The effect of temperature on water sorption for the two hybrid membranes is shown in Figures 7 and 8 , from which it is evident that the water sorption of the two hybrids is higher than that exhibited by the pre-swelled Nafion. In the case of hybrid membranes the higher water sorption is 
related to the capability of the siloxane domains to adsorb water molecules which overcomes the negative effects of the swelling treatment on the clusters morphology of the Nafion.

Comparing the isotherms of unmodified Nafion membrane with the isotherms related to hybrid membranes it is worth noting that at $40^{\circ} \mathrm{C}$ the difference in the water sorption is not very significant. This suggests that, at low temperatures, the siloxane domains do not affect significantly the water sorption, consequently the water sorption of unmodified Nafion 117 becomes slightly higher than that exhibited by the two hybrids. At $60^{\circ} \mathrm{C}$ the level of water sorption for unmodified Nafion 117 is similar to that of hybrid M/T 35/65, but is lower than for system M/T 65/35. At 70 ${ }^{\circ} \mathrm{C}$, on the other hand, the amount of water absorbed by both hybrids is higher than that of the unmodified Nafion 117. From these data it is clear that the presence of polysiloxane domains enhances the water sorption of the Nafion membrane at low water activity in the temperature range between 60 and $70^{\circ} \mathrm{C}$.

As for the dependence of water sorption on temperature the MT 65/35 membrane exhibits a maximum at around $60^{\circ} \mathrm{C}$. Below $60^{\circ} \mathrm{C}$ there might be a prominent effect due to the re-organization of the siloxane domains by thermal energy, which promotes the increase of water absorption with temperature. Above $60^{\circ} \mathrm{C}$ the effect of temperature on the exothermic interaction of water with ionic groups becomes more significant, resulting in a decrease in water sorption with increasing temperature. This can, therefore, account for the occurrence of a maximum in the water sorption characteristics of the hybrid membranes.

Conversely the water sorption of M/T 35/65 membrane increases with the temperature in the range between 40 and $70^{\circ} \mathrm{C}$. The polysiloxane domains in M/T 35/65 membranes exhibit a more compact and crosslinked network, compared to the more branched siloxane domains in the $\mathrm{M} / \mathrm{T} 65 / 35$ membranes. In fact, the presence of higher TEOS amounts densifies the polysiloxane network due to its higher reactivity with other alkoxysilane molecules [33]. This higher density in the M/T 35/65 polysiloxane domains affects the relaxations within the silica network, so that a maximum in the 
water sorption with temperature relationship can be expected to occur at a temperature higher than $70{ }^{\circ} \mathrm{C}$ (the maximum temperature used in the investigation).

The integral kinetic sorption curves of the hybrid M/T 65/35 at vapour water activity 0.5 and at temperatures of 60 and $70^{\circ} \mathrm{C}$ are shown in Figure 9. An integral kinetic sorption curve identifies the transient values of the sorption as a function of time in correspondence with a change of boundary conditions given by a step increase for the penetrant activity from zero to the test value. In general an increase of the temperature enhances the mobility of the penetrant decreasing the time necessary to reach the sorption equilibrium. In the case at hand it is evident that hybrid $\mathrm{M} / \mathrm{T} 65 / 35$ sorption is faster at $60^{\circ} \mathrm{C}$, which is likely to be due to the higher water sorption uptake of the hybrid M/T $65 / 35$ at $60^{\circ} \mathrm{C}$ compared to that at $70^{\circ} \mathrm{C}$. In effect, the molecular size of the penetrant (water) causes an increase of "free-volume" of the system available for the diffusive jumps of the penetrant. [34].

\section{Figure 9}

\section{Proton conductivity}

Proton conductivity originates from the mobility of the protons, which is promoted by the thermal activation and is aided by the presence of water inside the membrane. Consequently, proton conductivity decreases under conditions which promote a reduction of the equilibrium water content and is expected to increase with temperature, in view of its direct effect on the mobility of the conducting species. As a result of these two effects, it is possible that the actual variation of the proton conductivity with temperature either reaches a plateau or goes through a minimum if the water sorption decreases with the temperature. This second type of behaviour was actually found in commercial Nafion membranes at temperatures lower than those considered in this study [35]. Since, at the temperatures investigated and for vapour water activity equal to 1 , the amount of water sorbed is likely to be sufficient to create a large number of highly hydrated percolating pathways that are available for the flow of protons, the observed variation of the proton conductivity with 
temperature is mainly related to the activation of the Brownian proton mobility and can, therefore, be described by the Arrhenius equation, i.e.

$$
\sigma=\mathrm{A} \exp (-\mathrm{Ea} / \mathrm{RT})
$$

(where $\underline{\sigma}$ is the proton conductivity, Ea is the activation energy for the self-diffusion of protons, $\underline{\mathrm{T}}$ is the temperature in Kelvin, $\underline{\mathrm{R}}$ is the universal gas constant and $\underline{\mathrm{A}}$ is a pre-exponential coefficient). The applicability of the Arrhenius rate equation for all three systems is demonstrated in the plots in figure 10. In particular, according to equation (1), the slope of these diagrams corresponds to the activation energy Ea for the proton conductivity.

\section{Figure 10}

The system M/T 65/35 has the highest activation energy, while system M/T 35/65 has behaviour similar to unmodified Nafion 117, even though the proton conductivity is lower for both hybrids. Similar results were found in the literature concerning the proton conductivities of several inorganic-Nafion hybrids $[8,17]$, and could be due to any of the following: a) Lower mobility of the Nafion-hybrid network, b) Modification of the optimized ionic structure of the Nafion, and c) Higher tortuosity for the proton path in comparison to the unmodified Nafion [16]. These negative effects are significant at high water activity, where the water sorption in unmodified Nafion is already sufficient to promote high proton mobility. In fact, high water uptake causes the creation of percolative proton pathways saturated by free water that allow the occurrence of a proton structure transport mechanism (Zundel, Grotthus) in addition to the vehicular one [16]. Conversely, as the water activity is reduced it is expected that the effect of water sorption contribution related to the silica phase of the hybrids, at 60 and $70^{\circ} \mathrm{C}$, could overcome the other negative effects which depress the proton mobility described earlier.

Figures 11 and 12 report the proton conductivity data for the unmodified Nafion 117 and the two hybrids investigated, at different temperatures and two ranges of vapour water activities.. 
At the top of Figures 11 and 12 the vapour water activity values fixed by the salt solutions in the full range of temperatures studied are shown.

\section{Figure 11-12}

In particular it is evident that as the range of vapour water activity is reduced to values below 1 the expected effect of the hydrophilic silica on the proton conductivity related to the increase of the water sorption, becomes increasingly more significant. Consequently, for water activity between 0.4 and 0.5 the proton conductivity of hybrid M/T 65/35 becomes even higher than that of the unmodified Nafion 117.

It is worth noting that the proton conductivity data of the hybrids can not be solely related to the value of equilibrium amount of sorbed water. Accordingly, hybrid M/T 65/35 exhibits higher proton conductivity than $\mathrm{M} / \mathrm{T} 35 / 65$, even though at temperatures between 60 and $70^{\circ} \mathrm{C}$ the equilibrium water sorption of the two hybrids is quite similar.

Since the difference in the IEC values for the two hybrids is not very high it is likely that a key role might be played by the different morphology of the two hybrids. The proton conductivity of Nafion membrane is strongly dependent on the size of the ionic channels $[8,15]$, which is smaller at low water activity due to lower amount of water absorbed. The introduction of the siloxane hybrid networks in Nafion membranes has a constraining effect on their swelling capability, and exerts a negative effect on proton conductivity [8]. This could explain the higher proton conductivity, at low water activity, of hybrid M/T 65/35 compared to that of unmodified Nafion also at low temperatures $\left(40^{\circ} \mathrm{C}\right)$, despite the fact that the water content of the two membranes is quite similar. Furthermore the different morphology of the less compact network of hybrid M/T 65/35 could increase the amount of swelling of the ionic channels for similar overall water content of the membrane.

It could be hypothesized, therefore, that the different proton conductivity behaviour of the two hybrids is due to the difference in fraction of free water present for similar total water amounts in the membranes. 


\section{CONCLUDING REMARKS}

The aim of this work was to study the feasibility of producing novel Nafion- polysiloxane hybrid PEMs to enhance the proton conductivity at low water activity, which is a typical operating condition of hydrogen fuel cells.

The investigation has shown that the introduction of a polysiloxane network by the infusion of the precursor solution into a pre-swelled Nafion membrane, increases water sorption and proton conductivity. Furthermore it has been verified that the mere swelling and thermal treatment used to infuse the sol gel precursor solution into the membrane cannot account for the sorption features observable for hybrid Nafion membranes.

In particular, the siloxane domains were found to exhibits a complex behavior as they have an effect on the morphological structure of the Nafion, consisting of highly segregated hydrophobic and hydrophilic regions. This could affect the proton conductivity but at the same time it enhances the water sorption at low water activity at temperatures between 60 and $70^{\circ} \mathrm{C}$. At high water activity, the introduction of the siloxane neworks has an adverse effect on proton conductivity, despite the higher water content of the membrane. At lower water activity, on the other hand, the effect of the increase of water uptake at 60 and $70^{\circ} \mathrm{C}$, by the siloxane domains, becomes very predominant for proton mobility and, consequently, the hybrid membranes exhibit higher conductivity, and related fuel cell performance, than the unmodified Nafion.

A key parameter governing the performance of siloxane-Nafion hybrid membranes is the MPTS/TEOS ratio in precursor solution used.

The intrinsically higher activation energy for systems with higher MPTS/TEOS increases the proton conductivity in the temperature range $40-70^{\circ} \mathrm{C}$ within the mid-range of water activity $(0.4-0.5)$.

\section{REFERENCES}


RIVISTA PER VEDERE SE IL COGNOME DEVE VENIRE PRIMA DEL NOME. NATURALMENTE TUTTO DEVE ESSERE CONSISTENTE.

1. Zawodzinski, T.A.; Neeman, M.; Sillerud, L.O.; Gottesfeld, S. J. Phys. Chem. 1991, 95, 60406044.

2. Eikerling, M.; Kornyshev, A.A.; Kuznetsov, A.M. ; Ulstrup, J.; Walbran, S. J. Phys. Chem. 2001, $105,3646-3662$.

3. Matsuyama, M.; Kokufuta, E.; Kusumi, T.; Harada, K. Macromolecules 1980, 13, 196-198.

4. D. M. Bernardi, M. W. Verbrugge, AIChE J., 37(8), 1991, 1151-1163.

5. D. M. Bernardi, M. W. Verbrugge, J. Electrochem. Soc., 139(9), 1992, 2477-2491.

6. T.E Sprinter,T.A Zawodzinski, S.Gottesfeld, J.Electrochemical Society Vol 138, No 8, August 1991, 2334-2341.

7. Choy, P.; Jalani, N.H.; Datta, R. Journal of Electrochemical Society 2005, 152, 3, E84-E89.

8. C.Yang, S. Srinivasan, A.B. Bocarsly, S. Tulyani, J.B. Benziger, Journal of Membrane science $2372004,145-161$.

9. K.A.Mauritz, Materials Science and Engineering, C6, 1998, 121-133.

10. B. Baradie, J.P. Dodelet , D. Guay, Journal of Electroanalytical Chemistry 489 (2000) 101105.

11. Kenneth A. Mauritz,, John T. Payne, Journal of Membrane Science 168 (2000) 39-51

12. Leno Mascia, Luca. Prezzi , Journal of Materials Science 41 (2006) 1145-1155

13. P. Dimitrova, K.A. Friedrich, B. Vogt, U. Stimming, Journal of Electroanalytical Chemistry $532(2002) 75-83$.

14. C.Li, G. Sun,, S. Ren, J. Liu, Q. Wang, Z.W, H. Sun, W. Jin, Journal of Membrane Science $272,2006,50-57$.

15. Hsu, W.Y.; Gierke, T.D. Macromolecules 1982, 15, 101-105.

16. Kreuer, K.D; Paddison, S.J.; Spohr, E.; Schuster, M. Chem. Rev. 2004, 104, 4637-4678. 
17. K.T.Adjemian, S.J.Lee, S.Srinivisan, J.Benziger, A.B.Borocasly, J.Electr. Society, 149 (3) 2002, A256-A261.

18. K Wilson et al, Applied Catalysis A :General 228 ,2002, 127-133.

19. WM van Rhijn et al, Chem Comm 1998, 317-319.

20. Panster et al, Chem Abstr, 1989, 100, P122170j.

21. Sone,Y.; Ekdunge, P.; Simonsson, D. J. Electrochem.Soc. 1996, 143, 4, 1254-1259.

22. Del Nobile, M. A.; Mensitieri, G.; Manfredi; C.; Arpaia, A.; Nicolais, L. Polymers for Advanced Technologies,1996, 7, 409-417.

23. L.J Hobson et al, J. Electrochem Soc 148, 2001, 1185-1190.

24. Samms et al, J Electrochem Soc 1996, 143, 1498-1504.

25. Wilkie C.A. et al, J Appl Polymer Sci, 1991, 42, 901-909

26. Mascia L, Zhang Z. and Shaw S.J., Composites Part A, 27A,(1996),1211-1221.

27. Xenopoulos, C., Mascia L. and. Shaw S.J., High Performance Polymers, 13 (2001) 1 - 17

28. Deng et al. Polymer 39, 1998, 5961-.5972

29. Park H.B et al., Journal of Membr Sci, 245, 2005, 103-110

30. Adamson, A. W; Physical Chemistry of Surfaces (3rd Ed.), Wiley-Interscience, New York, 1976; Chapter 16.

31. Page, K.A.; Cable, K.M.; Moore, R.B. Macromolecules 2005, 38, 6472-6484.

32. Flory, P.J. Principles of Polymer Chemistry; Cornell University Press; Ithaca, 1953; Chapter 13.

33 Cihlar, J., Colloids and Surface A, Phys.Eng. Asp.1993, 70, 239-.

34. Vrentas, J.S.; Duda, J.L. Journal of Polymer Science 1977, 15, 403-416.

35. Sone, Y.; Ekdunge, P.; Simonsson, D. J. Electrochem.Soc. 1996, 143, 4, 1254-1259. 


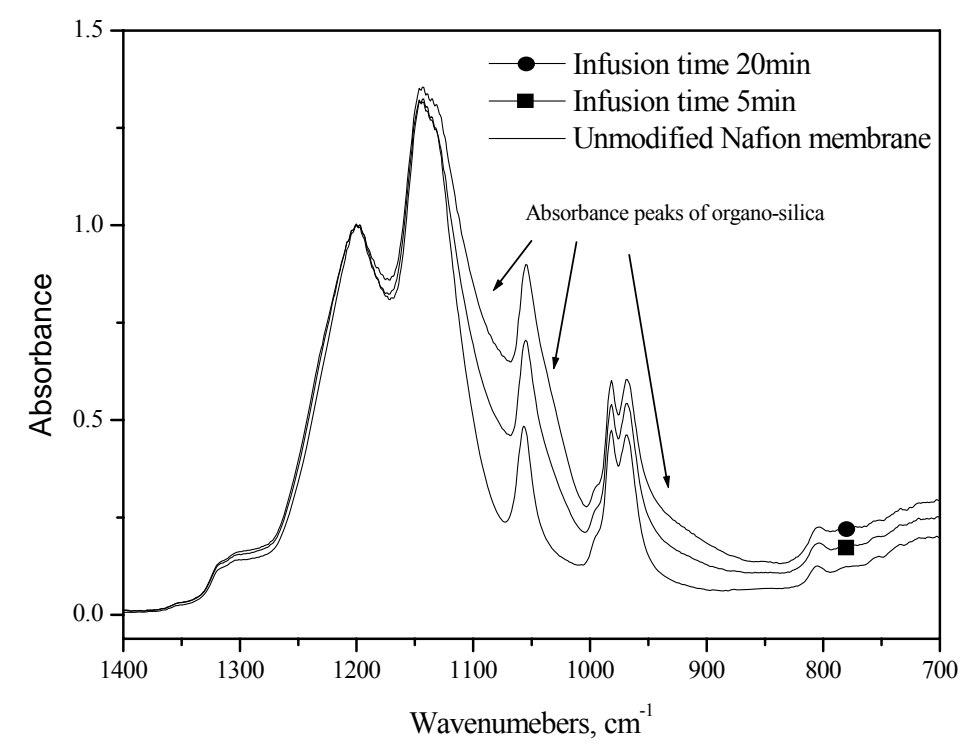

Figure 1: FT-IR transmissiospectra of the polysiloxane control (Weight ratio MPTMS/TEOS = $35 / 65)$, before and after the oxidation treatment. 


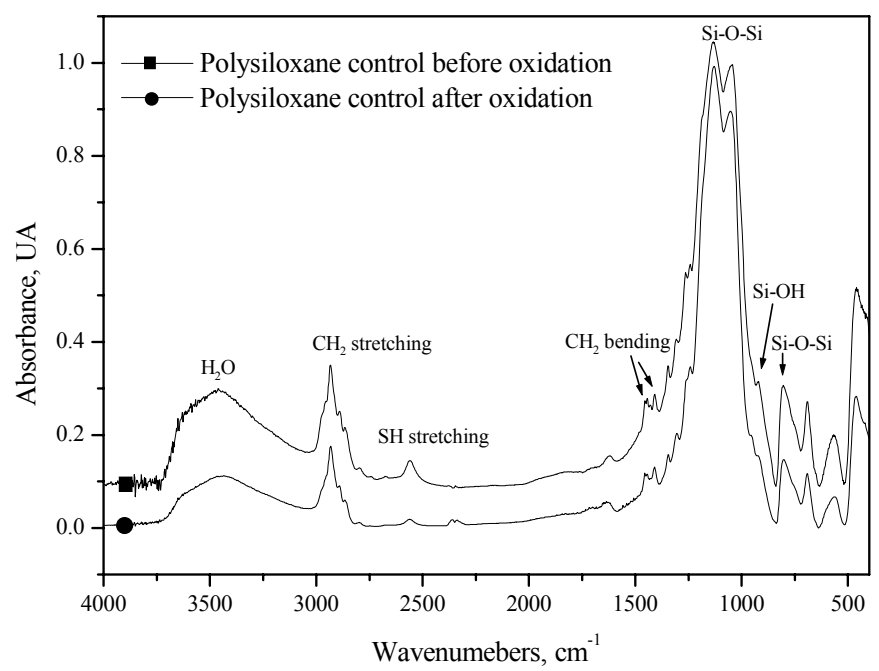

Figure 2: FTIR-ATR spectra of the Nafion 117 and hybrid membranes (Weight ratio MPTMS/TEOS $=35 / 65$ ) at 5 and 20 minutes impregnation time. 


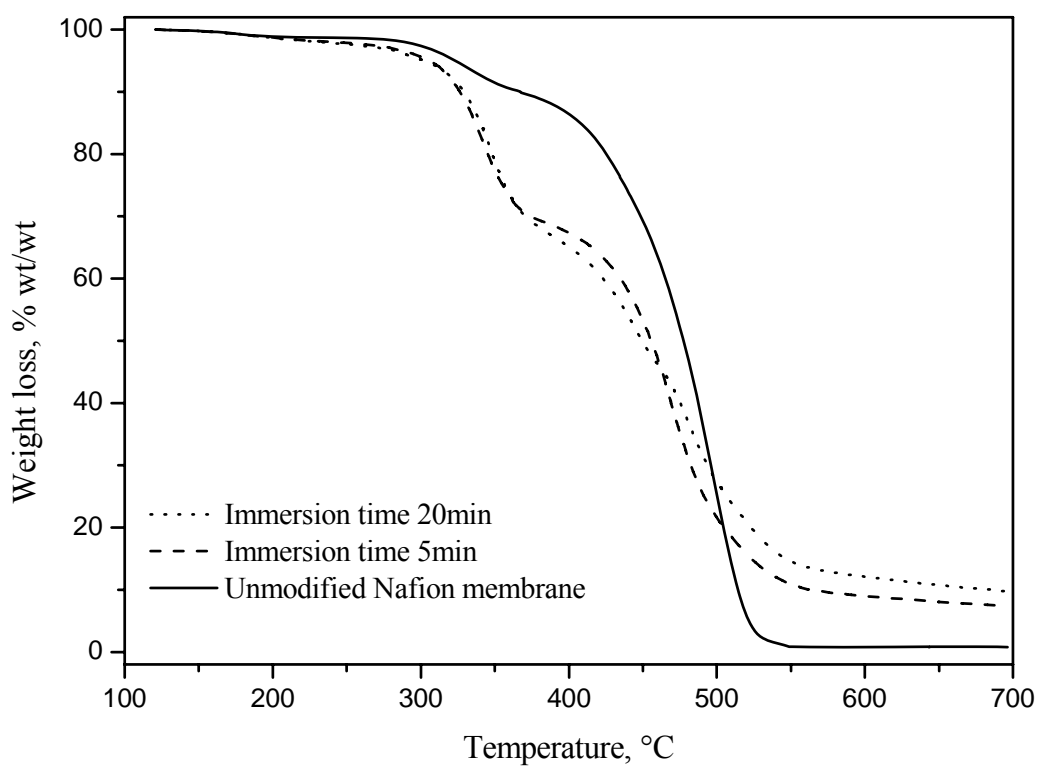

Figure 3 : Thermograms of unmodified Nafion and corresponding polysiloxane hybrids produced with different immersion times for MPTMS/TEOS ratio 35/65. 

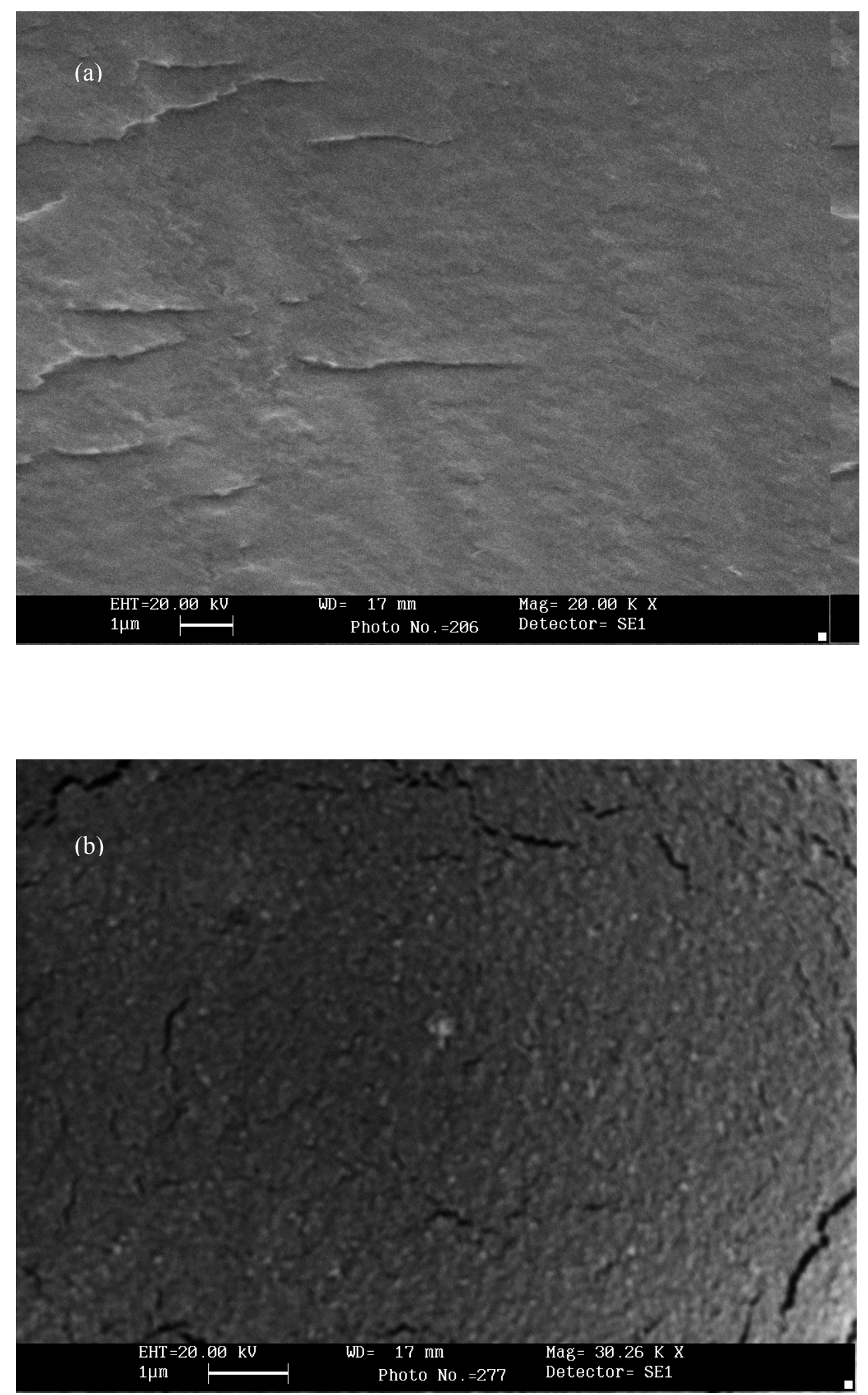

Figure 4: SEM micrograph of the cross-section of (a) unmodified Nafion membrane and (b) hybrid membranes with MPTMS/TEOS ratio of 65/35. 


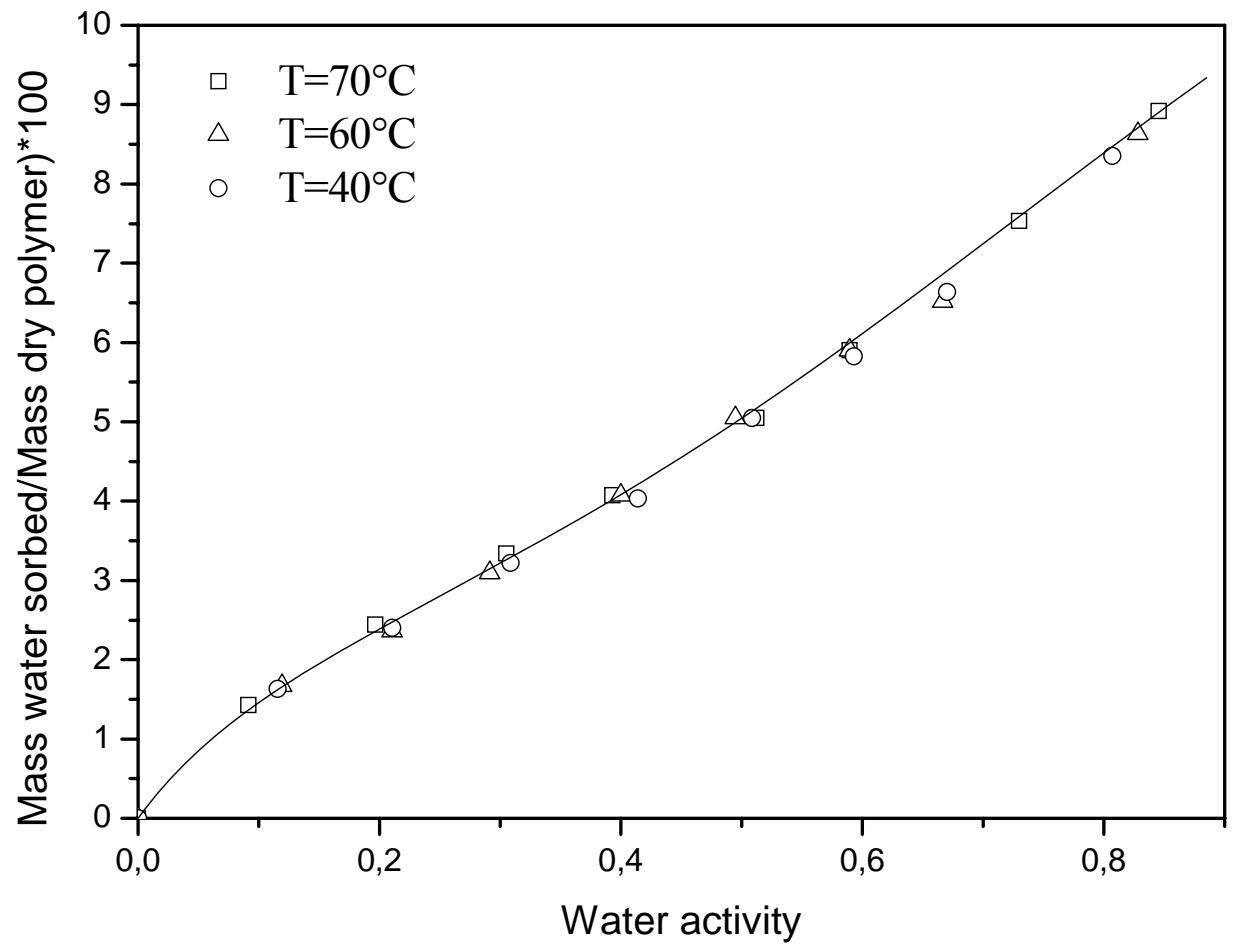

Figure 5: Water sorption isotherms of unmodified Nafion 117. The solid lines represent BrunauerEmmett-Teller (BET) fitting at $40-60-70^{\circ} \mathrm{C}$. 


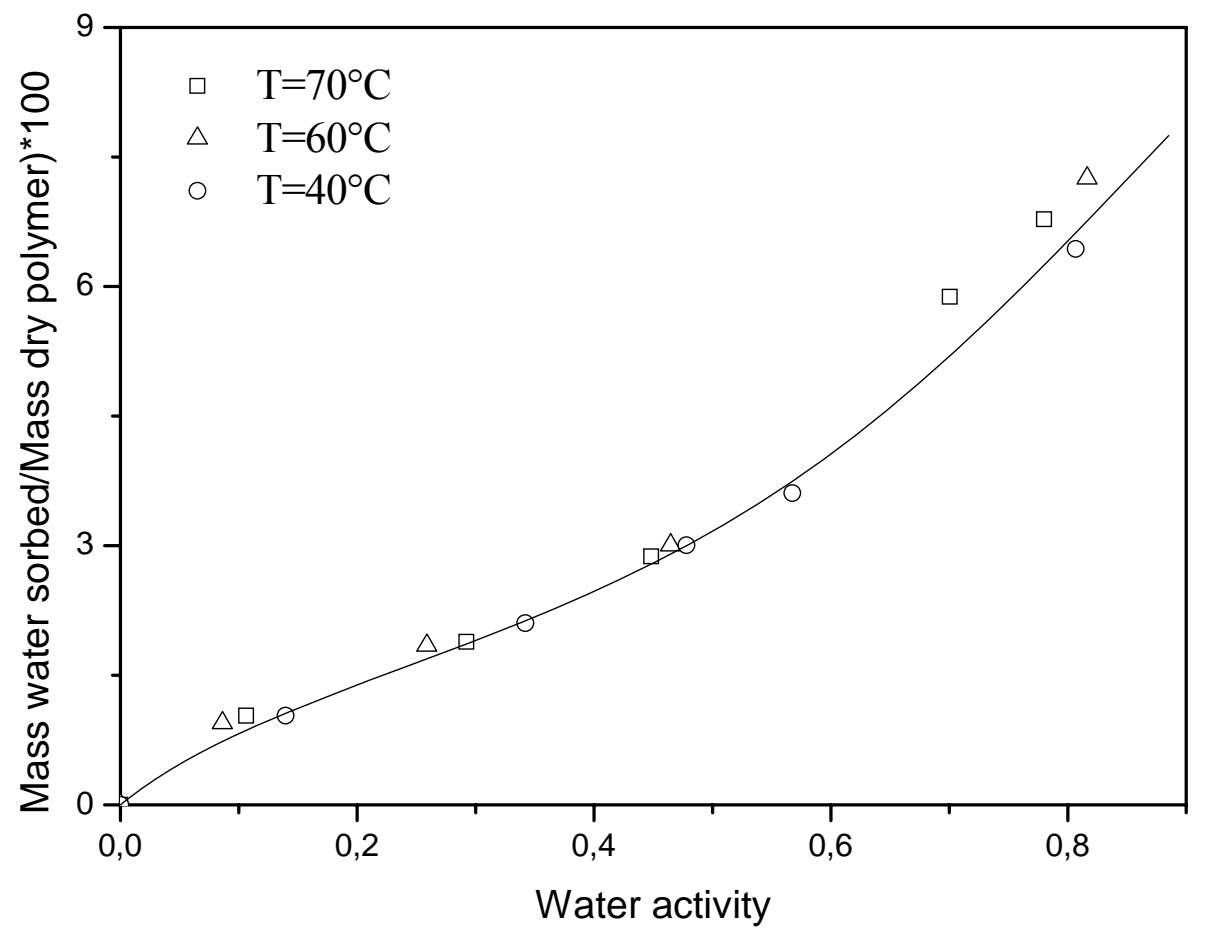

Figure 6: Water sorption isotherms of the swelled Nafion. The solid lines represent BrunauerEmmett-Teller (BET) fitting at $40^{\circ} \mathrm{C}$ and at $60^{\circ} \mathrm{C}$. 


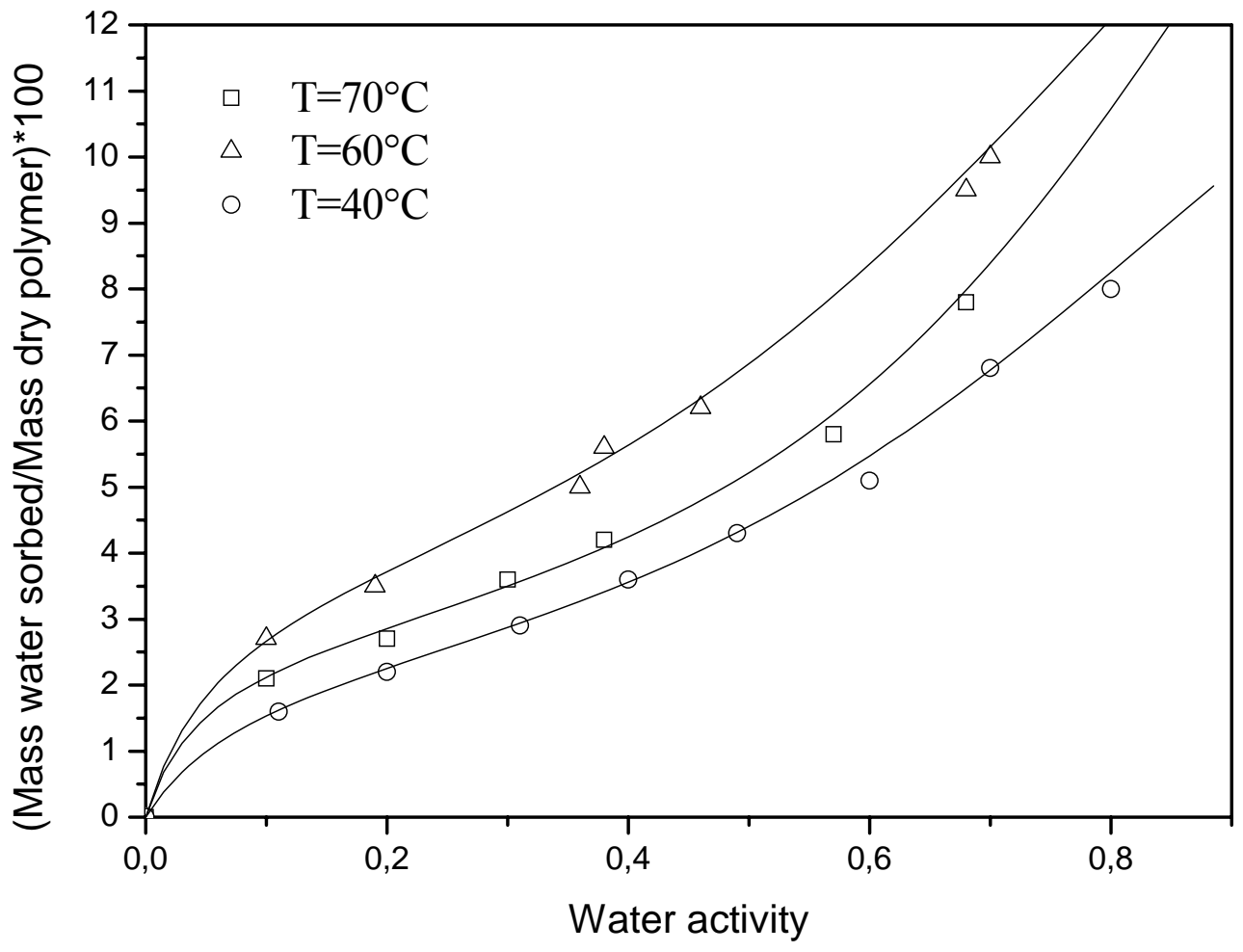

Figure 7: Water sorption isotherms of the hybrid M/T 65/35. The solid lines represent BrunauerEmmett-Teller (BET) fitting at $40-60-70^{\circ} \mathrm{C}$. 


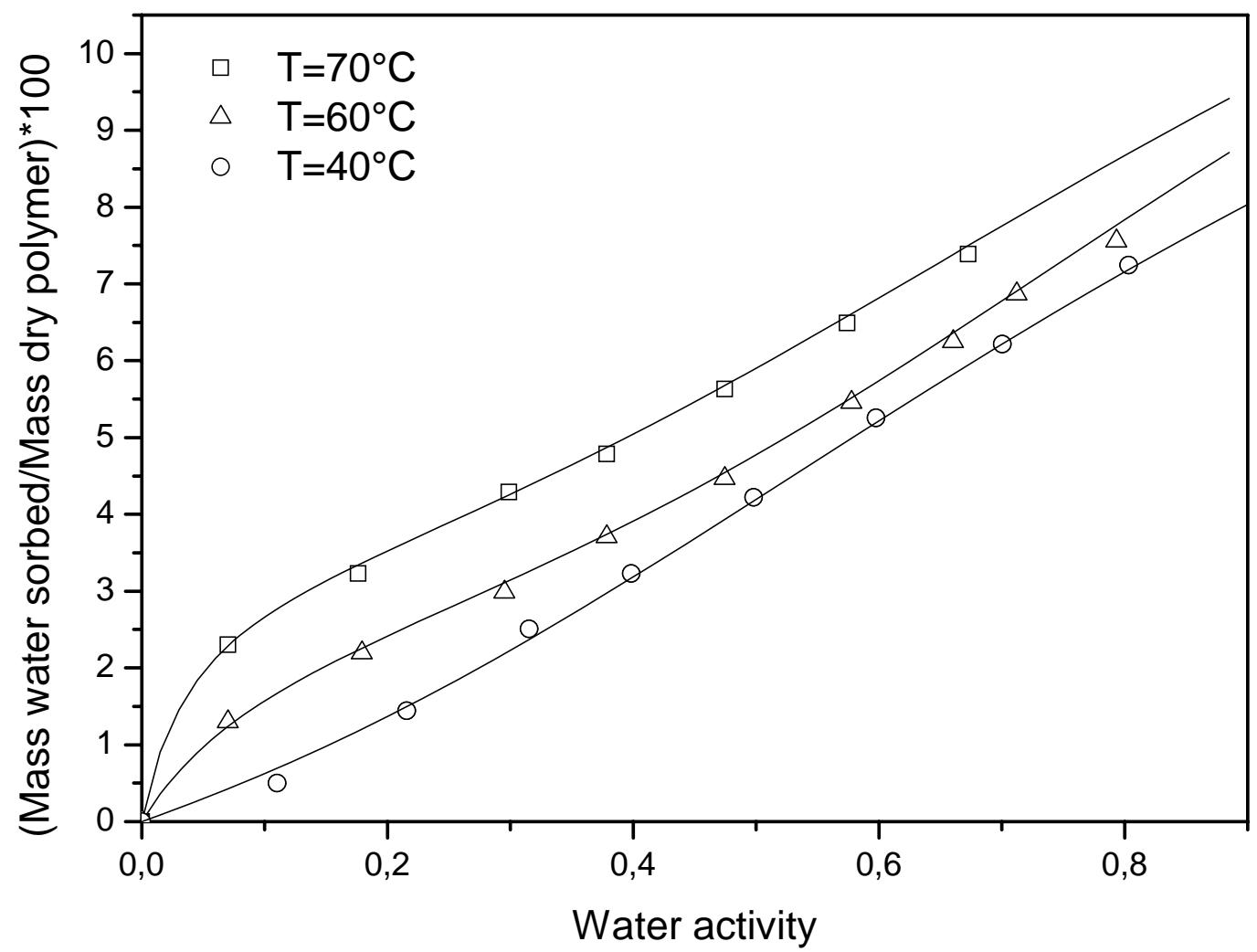

Figure 8: Water sorption isotherms of the hybrid M/T 35/65. The solid lines represent BrunauerEmmett-Teller (BET) fitting at $40-60-70^{\circ} \mathrm{C}$. 


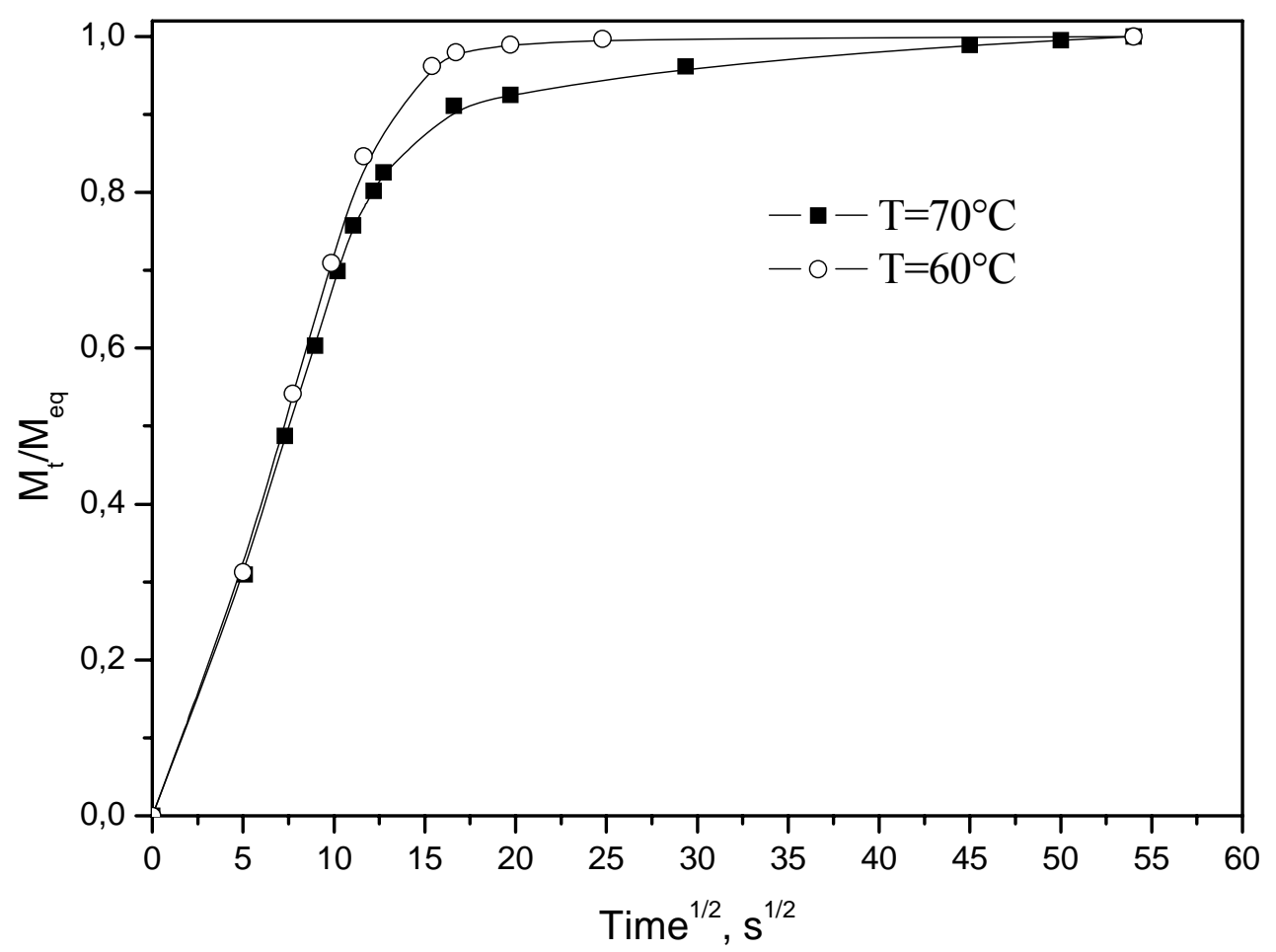

Figure 9: Integral vapour water kinetic sorption curves of the hybrid $\mathrm{M} / \mathrm{T} 65 / 35$ at vapour water activity 0.5 at 60 and $70^{\circ} \mathrm{C}$. 


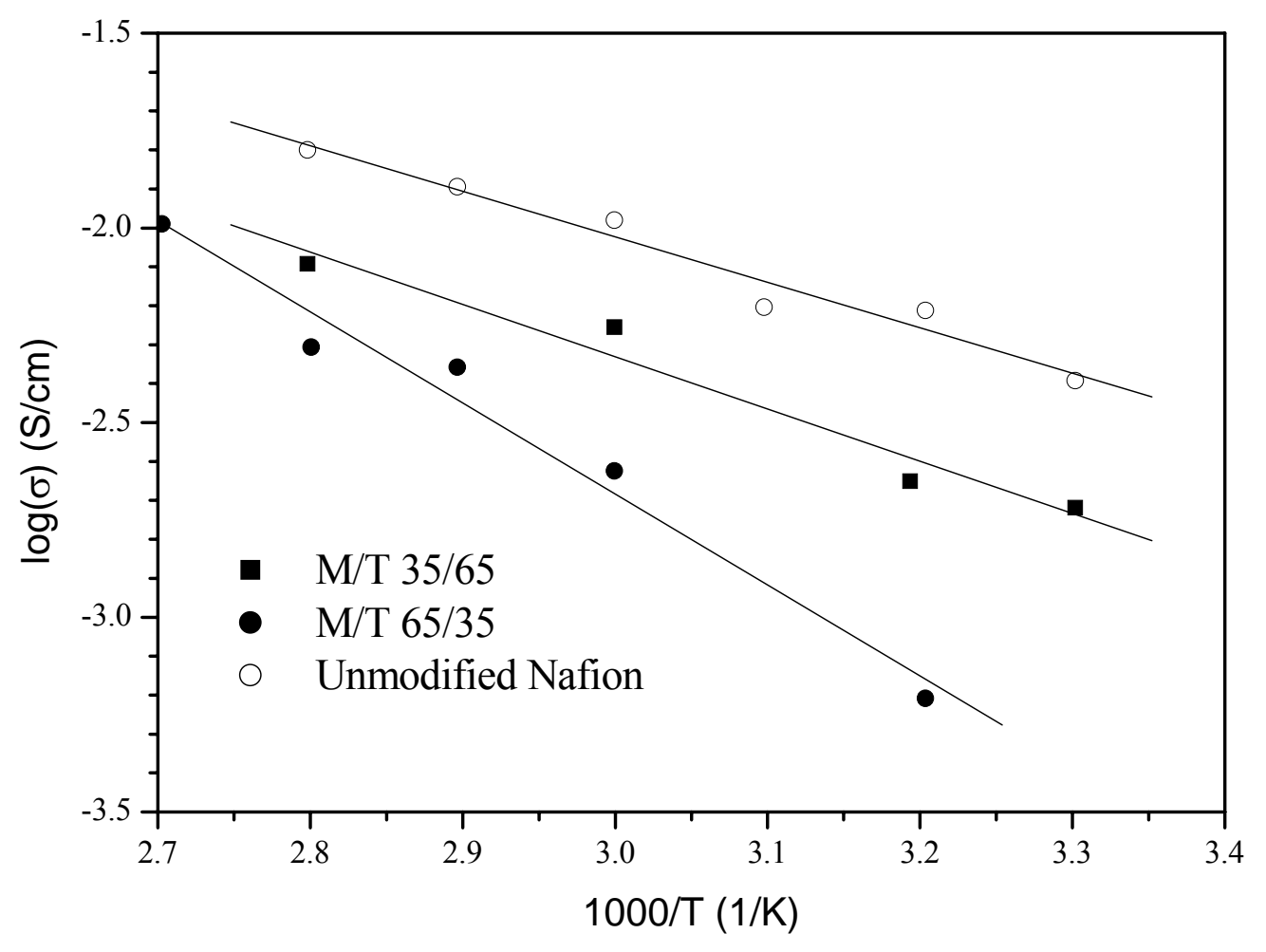

Figure 10: Proton conductivities as a function of temperature, at vapour water activity 1 of unmodified Nafion 117, hybrid M/T 65/35 and hybrid M/T 35/65. 

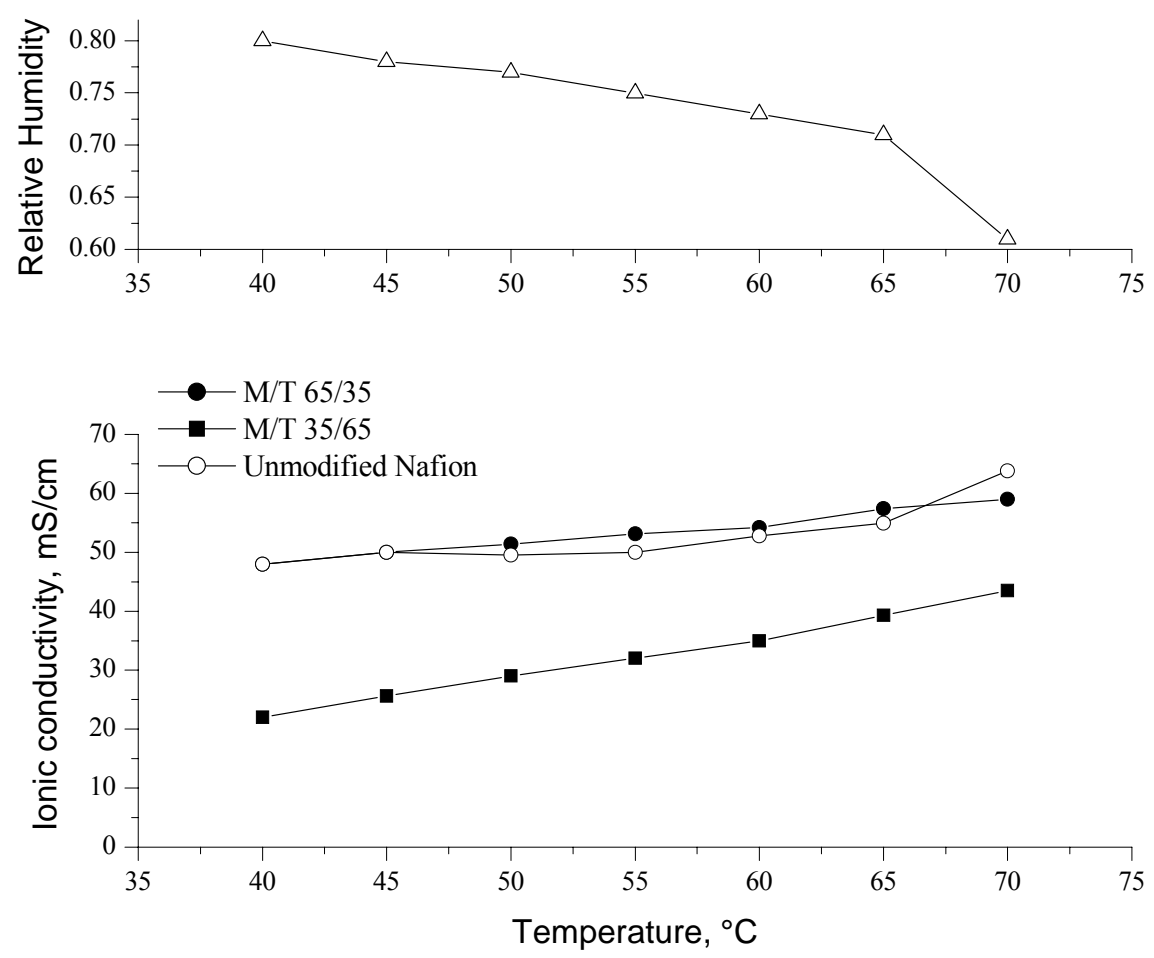

Figure 11: Proton conductivities and water activity of unmodified Nafion 117, hybrid M/T 65/35 and hybrid M/T 35/65, within the range of vapour water activity 0.7-0.8. 

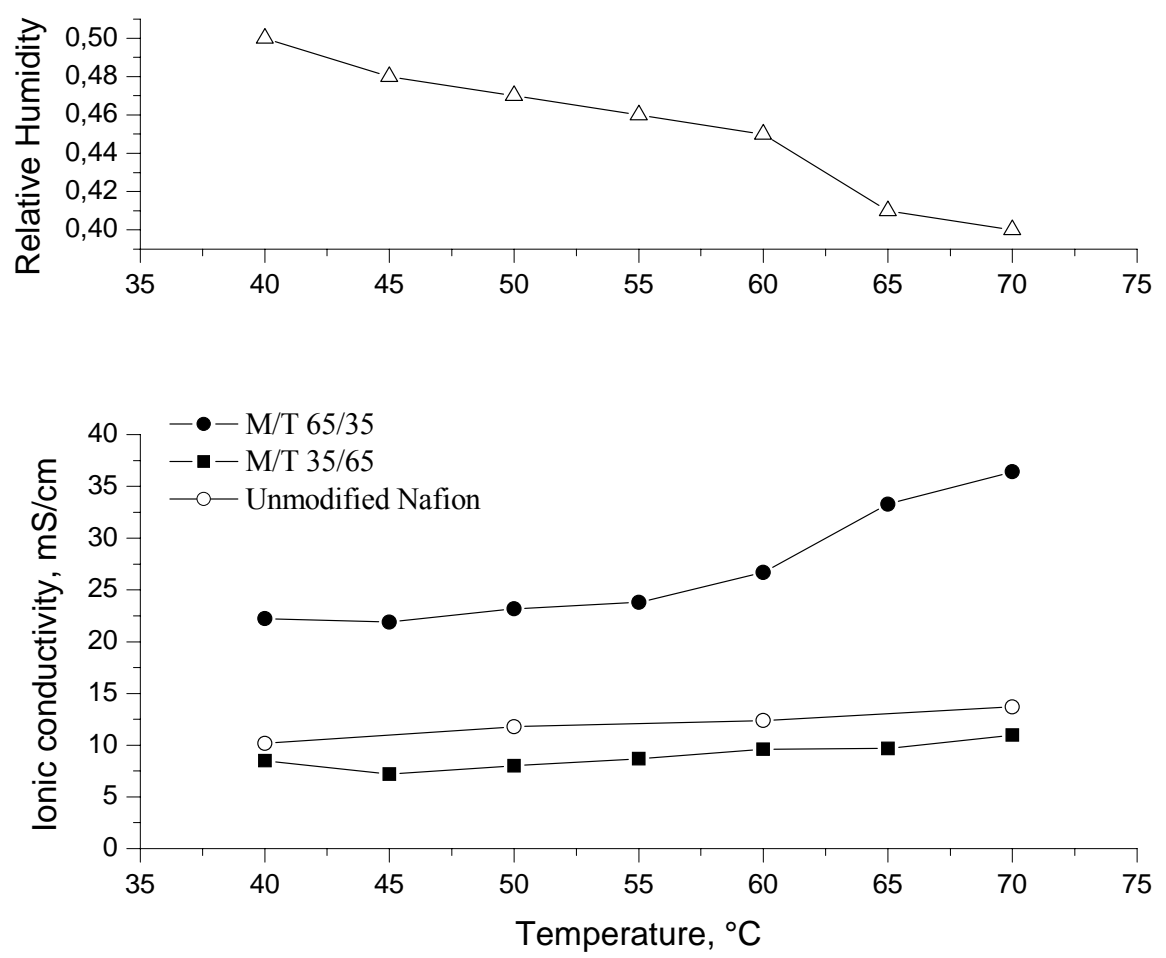

Figure 12: Proton conductivities and water activity of unmodified Nafion 117, hybrid M/T 65/35 and hybrid M/T 35/65, within the range of vapour water activity $0.4-0.5$. 
